\title{
El reconocimiento en el otro: autoafirmación y acción comunicativa en personas en extrema exclusión"
}

\author{
Nicolás Rojas Pedemonte**
}

Resumen: Este artículo analiza, a luz de una investigación cualitativa, cómo un grupo de personas en situación de calle se orienta a su constitución como actores sociales. Se indaga en aquellos aspectos relacionales que, en condiciones de profunda exclusión social, emergen como articuladores de acción colectiva. Así, se descubre en ellos un potencial transformador de su entorno y de sus propias vidas, en la medida que se reconocen entre sí como legítimos otros y titulares de derechos. Y en última instancia, se plantea la necesidad de aproximarse a sus experiencias de vida reconociendo sociológicamente sus competencias dialógicas y reflexivas, que les permiten autoafirmarse como sujetos.

Palabras clave: Exclusión, intersubjetividad, actores, calle, ciudadanía.

\section{Recognition in the other one: self assertion and communicative action in extremely excluded people}

\begin{abstract}
This article analyzes, in the light of a qualitative research, how a group of homeless orient themselves towards their constitution as social actors. We investigate those relational aspects that, in profound social exclusion conditions, emerge as collective action articulators. Thus, it is discovered in them a potential to transform their surroundings and environment and their own lives, insofar as they recognize each other as legitimate others and rights holders. Ultimately, there is a need for an approximation of their life experiences in sociological recognition of their dialogic and reflexive competences which permits self assertion as subjects.

Key words: Exclusion, intersubjectivity, actors, homeless, citizenship.
\end{abstract}

Con una reducción drástica de la pobreza y la indigencia en las últimas dos décadas, se presenta un panorama evidentemente alentador en Chile. Las cifras son elocuentes: desde el año 1990 a 2006, la pobreza habría disminuido de $38.6 \%$ a $13.7 \%$ y la indigencia,

* Se agradece a Soledad Moreno, Claudia Jaña, Edison Márquez, Mauricio Soto, Luis Ossa, Hernán Gutiérrez y Mónica Salinero, por su valiosa contribución.

** Universidad de Barcelona, Barcelona, España. Email: nicolasrojas@ gmail.com. 
de $13 \%$ a 3.2\% (CEPAL 2007). En la actualidad, Chile sería el país con la menor población de pobres en América Latina y en cuanto a indigentes, comparte esta categoría con Uruguay. Si bien estas cifras son motivo de celebración la tarea no terminaría aquí, pues emergen nuevos y complejos desafíos. Una sociedad que se desarrolla económicamente, requiere orientar su atención a la manera en que se distribuyen los beneficios y a sus consecuencias sociales, en términos de desigualdad, segregación y exclusión. Y, precisamente, en estas materias Chile tiene mucho camino por recorrer.

En dirección contraria a estas alentadoras cifras, la desigualdad ha aumentado en las últimas tres décadas y en la actualidad, Chile corresponde al décimo tercer país más desigual de un total de 177 países (Valda 2007). Y ciertamente, la capital Santiago grafica, como epicentro, estas tendencias. Desde los ajustes estructurales neoliberales de comienzos de los 80, no sólo ha aumentado su segregación espacial con la liberalización del suelo (Sabatini, Cáceres \& Cerda 2001), sino que se ha posicionado en la zona crítica de la desigualdad entre la urbes Latinoamericanas, con un índice de Gini próximo a 0.6, sólo superado en América Latina por las 2 principales urbes brasileras, Sao Paulo y Rio de Janeiro. De tal modo, auque proporcionalmente los pobres disminuyen, los efectos de estas tendencias macroeconómicas no reparan necesariamente la situación desfavorable que vivencian determinados colectivos excluidos.

Si el gran desafío consiste en incluirlos a todos y a todas en las experiencias modernizadoras de cada sociedad, en definitiva, significaría admitir que la ciudadanía se construye en el reconocimiento de las demandas de los grupos excluidos de aquello que el resto detenta por derecho (García \& Lukes 1999). Entonces, cuando surge la pregunta ¿quiénes son estos colectivos urbanos que no contarían con la plena facultad del derecho a tener derechos?, se visualizan diversos grupos excluidos y la respuesta se complejiza. No obstante, es posible afinar la vista y enfocarse a un tipo ideal como las personas en situación de calle (Mideplan 2005), considerando las ventajas heurísticas que conlleva esta estrategia weberiana a la hora de abordar fenómenos complejos, como lo es la exclusión. ${ }^{1}$

Efectivamente, en una experiencia de gobernaza, se ha diseñado e implementado recientemente en Chile una política pública para personas en situación de calle. Las demandas por ciudadanía, dirigidas desde la misma población objetivo y las

\footnotetext{
1 "Se entenderá la exclusión social como aquellos procesos dinámicos y reversibles de desvinculación social, que propician el aislamiento, el rechazo, el no acceso a la participación y a niveles de subsistencia socialmente aceptables. Serían los propios actores quienes encarnan, en particulares momentos y espacios, estos procesos. En una combinación de dimensiones económicas, políticas, socioculturales, biológicas y psicológicas, los actores participan con roles y sentidos particulares en las dinámicas de la exclusión. No obstante, en ningún caso serían éstos los portadores de la exclusión social, pues ésta no se refiere a un atributo intrínseco a su constitución como personas" (Rojas Pedemonte 2006). Por cierto, esta definición es tributaria de otras (Gacitúa 2000; Barros, de los Ríos, Torche 1995; Castel 1997).
} 
organizaciones de la sociedad civil que trabajan con ésta, alcanzaron validez frente a las autoridades públicas, y desde el año 2005 se trabajó en el diseño de esta política, para finalmente en noviembre de 2007 comenzar a implementarla.

Por cierto, esta política pública no se diseñó intuitivamente, pues contó con la experiencia de las organizaciones que han trabajado históricamente con este colectivo y de algunos de sus propios representantes. Sin embargo, aunque esta experiencia fue significativa en el diseño de la política, presentó dificultades para transmitirse sistemáticamente, pues se dispuso de escasos estudios que la condensaran. Principalmente, se contó, por un lado, con el Catastro Nacional "Habitando la Calle" (Mideplan 2005) que identificaba la magnitud y las características sociodemográficas de esta población y por otro, con "Voz y Ciudadanía" (Red Calle 2005) que sintetizaba los resultados de asambleas participativas regionales, donde esta población identificó los aspectos más significativos de su "problemática". Si bien estos documentos cuentan con información sumamente relevante, no dan cuenta de aquellas experiencias que estas personas desarrollaban, en ese entonces, como actores transformadores de sus vidas y su entorno. Durante este período las personas en situación de calle desplegaron iniciativas de autoafirmación, como reconocimiento de sí mismas y sus pares como ciudadanos.

Ejemplo de esto es que en Santiago -la ciudad con mayor presencia de estas personas en Chile; específicamente, 3458 (Mideplan 2005)- se desarrollaron experiencias de organización política por parte de este colectivo, entre otras iniciativas. En efecto, un logro histórico por parte de este colectivo fue posicionar a uno de sus representantes ${ }^{2}$ en la mesa técnica nacional de diseño de la política pública, en la que participaba el gobierno y las organizaciones del tercer sector involucradas en la temática.

Ciertamente, en este contexto emerge una serie de interrogantes, como por ejemplo: ¿Qué situaciones estructurales se constituyeron como condición de posibilidad para la visibilización de este colectivo y sus iniciativas de autoafirmación?, ¿cuál es el real impacto e injerencia que alcanzaron como actores movilizados en este proceso de construcción de ciudadanía?, ¿qué manera de relacionarse entre sí tiene este colectivo extremadamente excluido que, sin ser aún reconocidos socialmente como ciudadanos, puede desarrollar un sentido de pertenencia que los articula?

En efecto, las dos primeras interrogantes exceden las pretensiones de este artículo, no obstante, la última pregunta orientará la reflexión aquí presentada. Ciertamente, es pertinente preguntarse por determinadas características relacionales y culturales de los grupos excluidos que, como recursos, pueden constituirse en factores potenciadores de su

\footnotetext{
${ }^{2}$ En particular, Hernán "Lalo" Gutiérrez, dirigente de Revolución Kallejera, la organización de Personas en Situación de Calle que se forma durante el mismo año 2006.
} 
constitución como sujetos. ${ }^{3}$ Indagar en la experiencia que tiene del otro -y en particular de sus pares- la persona en situación de calle, se sitúa como el principal objetivo del desarrollo investigativo que aquí se expondrá. La agencia (Giddens 1998) o expresión subjetiva (Touraine 2006) alcanzada por este colectivo en la ciudad de Santiago, si bien no es inusitada a nivel mundial, merece la atención de la sociología. Indagar en las tendencias asociativas en los grupos excluidos resulta relevante en un contexto donde incluso la categoría trabajo -como trabajo flexible y precario (Sennett 2003) en el Chile contemporáneo- se ha debilitado como fuente identitaria (Garretón 2002, Touraine 2006).

\section{Elementos conceptuales}

Las ciudades globales (Sassen 1996) como Santiago de Chile, que se constituyen como "motores regionales" (Brenner 2003), se sitúan en una tensión entre los impulsos modernizadores y las fragmentación del espacio social que éstos, a nivel mundial, han conllevado (Moulaert, Martinelli, González \& Swingedouw 2007). No obstante, esta nueva configuración del espacio urbano se asocia a nuevas posibilidades de innovación social (Op. Cit.) de la mano de nuevas demandas y nuevos procesos de reconfiguración de la ciudadanía (García, 1996; García \& Lukes 1999). Por su parte, la perspectiva de la Social Innovation View releva las luchas y resistencias de amplios sectores perjudicados y excluidos por (y de) la globalización neoliberal. Con lo cual, las experiencias asociativas y de agencia o acción social por parte de los sectores excluidos se constituyen en un aspecto fundamental de la nueva faz de las urbes globales. Ciertamente, "el espacio de la ciudad globalizada es un espacio que está muy despierto" (Sassen 2004) y se abren nuevas e inusitadas posibilidades de autoafirmación de los sujetos.

\footnotetext{
3 Se entenderá por "sujeto" a un actor individual concreto que se orienta socialmente con un sentido autofundamentado. Al ser autofundamentado el sentido de su accionar, es el mismo el individuo su sujeto y no el sentido que desde él se proyecta o se le confiere externamente. Es un individuo que, utilizando ex profeso (con cierto margen de intencionalidad y libre albedrío) sus competencias naturales y socializadas, actúa en pos de convertirse en fundamento de los procesos sociales que le involucran. Un actor capaz de reflexionar -con un grado suficiente de autonomía- acerca de su propia existencia y necesidad de coordinación con otros válidos sujetos. Este sujeto individual no cae en un solipsismo cartesiano, sino que reconoce la necesidad de relacionarse intersubjetivamente y alcanzar acuerdos mediante el diálogo, simultáneamente, protegiendo su individualidad y validando la de sus interlocutores. Ciertamente la noción de sujeto utilizada en este documento se condice, en gran parte, con la propuesta por Touraine (1994) en la última etapa de su obra, encarnada en la noción "sujeto personal". Este sociólogo francés entiende "el sujeto como la reivindicación de ser un individuo, de llevar una vida personal, generalmente contra los aparatos y las técnicas de poder, pero utilizando también la fuerza de la razón para resistir al poder arbitrario o a las presiones de la comunidad. El sujeto no se forma alejándose del cuerpo y del ello, del mundo del deseo, y la modernidad no consiste en aplastar la afectividad y los lazos interpersonales en nombre de la razón" (Touraine 1994: 271). Si bien esta noción de sujeto -estrechamente vinculada a la noción original aristotélica (Aristóteles 1998)- hace referencia a individuos, evidentemente dista del individualismo metodológico, por su engarce con la colectividad, su resistencia frente a las arbitrariedades sociales y su apelación a los principios ilustrados de Razón y Libertad.
} 
En los espacio de desencuentro y segregación, emergen, a contrapelo, impulsos de reconocimiento y encuentro entre sujetos que se identifican como pares, distintos e iguales (Touraine 2000a). Mediante la experiencia dialógica, expresada en la acción comunicativa (Habermas, 1999) estos sujetos se reconocen como otros válidos en la convivencia. En este sentido, Humberto Maturana (1990) reconoce que lo propio de las especie humana es el desarrollo de un lenguaje que le permite resolver problemas mediante la conversación. El lenguaje, como coordinaciones de acciones consensuales (Maturana 1990), efectivamente, sería la habilidad propia de los seres humanos, como una especie evolucionada que no necesariamente reproduce mecánicamente sus acciones. Y por cierto, estas competencias lingüísticas no serían privativas de determinados sectores sino más bien, universales (Chomsky 2001).

La acción comunicativa se basaría en un fenómeno intersubjetivo, que en términos de la tradición fenomenológica, estaría dado por la pertenencia a un mismo flujo de experiencia, donde el sujeto participa en la simultaneidad vívida del "nosotros". Concretamente, esto respondería a la apresentación del otro, como reflejo de una conciencia en otra -como plantea Husserl (1985)- en un ámbito de experiencia compartido. En términos schellerianos respecto a la tesis general de la existencia del alterego, el otro y su pensamiento -a diferencia del propio- se manifiesta como presente. De tal modo, se percibiría al otro como un flujo de consciencia posible de asir en su presente, a través de las actividades comunes y concomitantes. Evidencia de esto sería el hecho de "que cada uno puede experimentar pensamientos y actos del otro en el presente vívido, mientras que ninguno puede captar sus propios pensamientos y actos salvo como pasado y por medio de la reflexión, yo sé más del otro y él sabe más de mí que lo que cualquiera sabe de su propio flujo de consciencia. Este presente, común para ambos, es la esfera pura del "nosotros" (Schutz 1974: 171). Con esta inmediatez entre las conciencias, donde incluso resultando recurrente la dificultad de distinguir si una idea es propia o es del otro, la intersubjetividad y la apresentación del otro no viene más que a ampliar el espectro intelectivo de los sujetos.

En el actual estadio de la modernidad, los sujetos contarían no sólo con competencias comunicativas, sino además alcanzarían capacidades intelectivas y reflexivas que le otorgan una especial comprensión de la situación y el entorno en que viven (Beck 1996, Giddens 1998, Habermas 1999, Touraine 2006). En tales condiciones, con estructuras que no sólo limitan, sino que además habilitan (Giddens 1998), los sujetos son capaces de reconocer como legítimos sus impulsos de autoafirmación. Y por cierto, la experiencia intersubjetiva no hace más que potenciar este empoderamiento. De tal modo, los individuos se constituyen como sujetos transformadores que, intersubjetivamente, despliegan acciones en pos del reconocimiento de los derechos y la dignidad humana que éstos ratifican (Touraine 
2006). En una sociedad con mayores niveles de historicidad, ${ }^{4}$ que no sólo se reproduce sino también se transforma, los sujetos -pertrechos de nuevas capacidades y con mayores espacios de indeterminación- participan como "agentes del cambio" (Giddens 1998, Beck 1996, Touraine 2006). En estricto sentido, "desde la perspectiva de la formación de sujetos, el tema es el aprendizaje de las expectativas recíprocas en los vínculos con las(los) otras(otros): ¿Qué derechos tengo? ¿Cuáles son mis responsabilidades? Este proceso implica un doble juego en el que simultáneamente reconozco cuáles son las responsabilidades del otro hacia mí (y mis derechos) y aprendo cuáles son mis responsabilidades hacia el otro. Proceso que no sólo implica este aprendizaje de expectativas y conductas responsables sino también cómo definir la amplitud del espacio de la responsabilidad de cada sujeto" (Jelin 1993: 34).

Por cierto, este impulso transformador no se remite a quienes resultan beneficiados por la modernización neoliberal, sino más bien es constitutiva de aquellos sujetos excluidos que, desde el desgarro y la negación, reclaman el reconocimiento social de sus singularidades (Touraine 2006). En consecuencia, las urbes de los países en desarrollo, caracterizadas por diversas experiencias de modernidad y dualismo estructural, no se quedarían al margen de estas tensiones, sino más bien las entrañan con diversos matices y dinámicas. En efecto, las ciudades globales del tercer mundo cuentan con fuertes desgarros, encarnados -en muchos casos- en sectores asociados a lo que "Marx hubiera llamado Lumpen, pero que aquí se vuelven actores políticos" (Sassen 2004). Y es precisamente en las esferas más cotidianas de la vida urbana, donde, en definitiva, el reconocimiento de sí mismo -y por lo tanto, también del otro- se constituye como la lucha política por excelencia, en la sociedad post industrial globalizada (Garretón 2002, Touraine 2006). De tal manera, hoy se presencia diversas "demandas ciudadanas que surgen de lo diferentes mundos cotidianos de la vida, intersubjetivamente creados a partir de situaciones de interacción concreta en marcos sociales históricamente específicos -concepto de la sociología fenomenológica que tiene una importante labor que cumplir en el estudio del bienestar social" (Alonso 1997: 24).

Un paradigma de estos sectores lo constituyen las personas en situación de calle. Como el grupo más desventurado dentro del colectivo de los "homeless" (Edgar \& Meert 2005), sus capacidades y recursos suelen comúnmente ser obnubilados por sus explícitas carencias. No obstante, si bien se reconoce en ellos un profundo deterioro psicosocial (Ossa 2005), también - como lo evidencia un reciente estudio estadístico multivariable (Rojas Pedemonte 2007) - poseen diversos recursos y capacidades que les permiten situarse en un contexto tan adverso como la calle. En efecto, se han identificado significativos

${ }^{4}$ La noción de historicidad alude a la capacidad propia de las sociedades de transformarse a sí mismas y se expresa, en concreto, como la "acción ejercida por la sociedad a partir de su actividad sobre sus prácticas sociales y culturales, mediante la combinación de tres componentes: el modo de conocimiento, que constituye una imagen de la sociedad y de la naturaleza, la acumulación que extrae una parte del producto disponible, y el modelo ético que capta e interpreta la capacidad de acción de la sociedad sobre sí misma" (Touraine. 1995: 354). 
niveles de autosuficiencia en sus estrategias ${ }^{5}$ de supervivencia (Rojas Pedemonte 2007), las cuales se asocian a determinados oficios del mercado formal e informal. $\mathrm{Y}$ es, precisamente, en torno a estas competencias y su carácter resiliente, que personas gravemente excluidas como éstas, apelan a su reconocimiento como legítimos sujetos. Históricamente, la expansión de la ciudadanía (citizenship) - como documenta Marshall (1998) - ha sido diacrónica en sus aspectos civiles, políticos y sociales, y en los últimos siglos ha respondido a la emergencia de diversas poblaciones excluidas. ${ }^{6} \mathrm{Y}$ ciertamente, en diferentes latitudes la población "homeless" ha dado signos de no querer mantenerse al margen (Cress \& Snow 1996).

\section{Aspectos metodológicos}

Existe profunda distancia entre las ciencias sociales y la experiencia cotidiana de las poblaciones excluidas. Por un lado, la manera en que estas personas se relacionan con su entorno social y entre sí, muchas veces es desatendida en pos de detalladas caracterizaciones de sus atributos individuales. Y por otro, esta distancia se acrecienta por la reticencia generalizada de los sociólogos a experimentar de cerca una vivencia cotidiana indeseable en términos materiales y sociales.

No obstante, para dar respuesta a la interrogante que guía este documento, resulta apropiado acortar estas distancias. Para aproximarse a la experiencia relacional de estas personas, se requiere de un abordaje cualitativo en la línea de la tradición etnomodológica (Garfinkel 1996). Sólo mediante un proceso investigativo que priorice la proximidad con la realidad inmediata será posible contrastar la siguiente hipótesis de trabajo: a pesar de su no reconociendo social, las personas en situación de calle, intersubjetivamente son capaces de reconocerse a sí mismas y a sus pares como agentes transformadores, es decir, como sujetos capaces de protagonizar cambios en sí mismos y en su entorno.

Dar cuenta cómo los sujetos excluidos se reconocen en el ámbito de sus relaciones intersubjetivas, implica orientarse a partir de determinadas premisas metodológicas. De carácter fundamental es la necesidad de romper con el "desnivel metodológico" entre el investigador y el investigado, estableciendo un diálogo de igual a igual (Habermas 1999). Lo cual, en definitiva, implica reconocer las competencias interpretativas y comunicativas de los sujetos estudiados y los límites inherentes al investigador. En pos de aminorar los límites interpretativos-experienciales del investigador es necesario establecer una

\footnotetext{
${ }^{5}$ Ciertamente entendidas como prácticas con basamento instrumental y amplio manejo de recursos propios del contexto social que vivencian: la calle.

6 "La ciudadanía y los derechos no hablan únicamente de la estructura formal de una sociedad; además, indican el estado de la lucha por el reconocimiento de los otros como sujetos de 'intereses válidos, valores pertinentes y demandas legítimas'.” (García Canclini 1995: 21).
} 
interacción basada en la acción comunicativa. Esto significa una relación orientada al diálogo y al respeto por los argumentos del otro, donde primen las pretensiones de validez por sobre las de poder. Lo cual resulta pertinente sobre todo con personas excluidas que han desarrollado actitudes reticentes frente a los cotidianos tratos arbitrarios $\mathrm{e}$ intervenciones paternalistas por parte de los incluidos. De tal manera, se reconocen los beneficios de generar un proceso investigativo de carácter participativo que sea construido procesualmente mediante el diálogo con y entre las personas en situación de calle. Esa interacción comunicativa, orientada al entendimiento por sobre la arbitrariedad, elimina los sesgos del investigador en una dialéctica coeducativa entre sujetos (Flecha, 2004; Freire, 2004). En la línea de la Metodología Comunicativa Crítica, se admite que mediante un "diálogo igualitario -basado en pretensiones de validez- (en el original el texto entre guiones se encuentra en la nota al pie) y la reflexión conjunta, se puede llegar a comprender los procesos que generan la exclusión y la inclusión social en la realidad social" (Flecha, et al. 2004: 27).

Desde esta perspectiva metodológica, se desarrolló una experiencia de investigaciónacción participativa (IAP) con un grupo de personas en situación de calle de la ciudad de Santiago. Bajo el alero de la Fundación Hogar de Cristo, un sociólogo, ${ }^{7}$ una psicóloga y 6 personas en situación de calle conformaron un grupo que recorrió semanalmente -durante todo el año 2006- las calles de Santiago buscando y visitando a sus pares, ofreciendo, únicamente, diálogo y cálida compañía en la frialdad de la noche. ${ }^{8}$ Así el grupo se autodenominó "Corazón en la calle" y aunque utilizaban recursos de la Fundación Hogar de Cristo, se autodefinían como independientes de toda institución. En efecto, ellos lideraban las gestiones y protagonizaban cada una de las actividades realizadas, mientras los investigadores sólo actuaban como colaboradores o facilitadores. ${ }^{9}$ Con pleno protagonismo de las mismas personas en situación de calle, el grupo delineó participativamente sus actividades y propósitos, generándose así una experiencia de intervención social recursiva y

\footnotetext{
${ }^{7}$ El presente autor.

${ }^{8}$ Así también se desarrollaban otras dos actividades: reuniones diurnas semanales, que se constituían en el espacio de diálogo grupal, donde se trataban temas personales y grupales, así como también de planificación y evaluación de las visitas o "rutas". Y por lo demás, se realizaban semestralmente viajes recreativos fuera de la ciudad. Por su parte, durante las reuniones diurnas participaba siempre la psicóloga, mientras que en las "rutas" nocturnas, el sociólogo, acompañado generalmente de una voluntaria de la Fundación y en ocasiones, alguna persona invitada por el grupo. No obstante, las actividades generalmente contaban con la presencia de los dos profesionales.

${ }^{9}$ Las reuniones diurnas se realizaban, a partir de una solicitud formal del grupo a la Fundación Hogar de Cristo, en las dependencias de ésta y así también las "rutas" nocturnas, en furgones con conductores también facilitados por la misma institución. Ejemplo de este nivel de autogestión y autonomía es que los furgones durante las rutas no portaban distintivos de la fundación. Así también ellos guiaban las rutas nocturnas y tomaban la iniciativa en el contacto con las personas visitadas, mientras los investigadores figuraban como "amigos" o invitados. Sin embargo, fuera de las actividades grupales la psicóloga desarrollaba un acompañamiento a los proceso individuales que cada persona vivenciaba, aunque este servicio constituía una prestación más de las cuales podía obtener cualquier persona en situación de calle en la Fundación Hogar de Cristo.
} 
a la vez, recíproca. Recursiva en la medida que el sentido de la intervención se dirigía desde y hacia los mismos participantes del grupo, y recíproca por cuanto los profesionales de las ciencias sociales no sólo participaron colaborando e investigando, sino además como observadores y "aprendices" (Colectivo OIE 1993).

Como toda IAP, contó con aquellos objetivos propios de la actividad desarrollada y con aquellos investigativos, específicamente, orientados a la intervención social. Pues, en efecto, se trató de complementar las dimensiones teóricas y prácticas, interpretando las prácticas sociales, no sólo para identificar posibles intervenciones, sino también para reflexionar sobre sus posibles aplicaciones en un nuevo contexto, tan real y vivo como aquel (Rodríguez Gabarrón \& Hernández Landa 1994). En estricto sentido, el objetivo propio de la actividad consistió únicamente en establecer vínculos con sus pares (tanto los visitados como los del mismo grupo), mediante el acercamiento dialógico, en palabras de las personas en situación de calle "conocer y acercarnos a "nuestros iguales", a "gente con nuestro problema". Mientras que, por otro lado, se tuvo objetivos esencialmente dirigidos "a la intervención, a la obtención de algún tipo de efecto, por pequeño que éste sea, sobre la realidad social" (Vallejos, Ortí \& Agudo 2007: 302) y personal. Estos objetivos, por un lado, apuntaron a la sensibilización intersubjetiva y por otro, a reconocer proyectivamente las oportunidades que presenta una experiencia participativa como ésta, para la intervención con estas personas y para la sociología.

Por la manera participativa y procesual con que se establecieron los lineamientos y los objetivos de esta experiencia, ${ }^{10}$ ésta se ciñe a la tradición de la IAP. Contraria a la dinámica tecnocrática de las investigaciones, donde determinada institución prefija objetivos y solicita su cumplimiento a los técnicos, ésta ha sido "una forma de intervención sobre la realidad social que pretende conocer como requisito previa y concientemente ligado a la necesidad de actuar" (Ibidem). En última instancia, la dimensión epistemológica de la investigación (Ibáñez 1986), es decir, el para qué y para quién, se determinaron participativamente a luz de un compromiso institucional y científico por el beneficio del mismo grupo excluido. Así, lo beneficioso fue determinado desde ellos mismos, pues la IAP apunta a "proporcionar una ocasión para expresarse a sectores más o menos estructurados, pero cuyos puntos de vista suelen ser obviados de forma casi sistemática" (Vallejos, Ortí \& Agudo 2007:294). En tal contexto, el carácter participativo y flexible de la investigación, propio de la tradición cualitativa, permitió reformular y reorientar el proceso a la luz del constante diálogo.

Sin lugar a dudas, si lo que orienta una investigación es la necesidad de indagar en las reales posibilidad de constitución de las personas en situación de calle como actores transformadores (Márquez 2006), es importante apelar a la propia experiencia e

\footnotetext{
${ }^{10}$ Donde la Fundación Hogar de Cristo no prefijó objetivos, sino más bien actuó como facilitador en el cumplimiento de las decisiones tomadas por el grupo.
} 
interpretación que ellos tienen de la realidad. Si apostamos a estudiarlos como sujetos y no agentes pasivos, es indispensable establecer espacios de reflexión común, donde sea posible visibilizar aquello constitutivo de los actores: el sentido de autoafirmación de sus singularidades frente a la negación social de ellas (Touraine 2000b).

En concreto, en este grupo participaron ocho personas en situación de calle, no obstante, en razón a la persistencia de su participación, se ha considerado integrado, en específico, por 6 miembros. La espontaneidad con que se conformó este grupo, le aportó un carácter heterogéneo en cuanto a trayectorias vitales y atributos sociodemográficos. No obstante, hubo una característica que fue común: entre sí eran perfectos desconocidos. El grupo se compuso de tres hombres y tres mujeres de diversas edades. Respecto a los otros dos participantes, uno correspondía a un miembro inicial que, producto de un accidente y posterior desaparición, no alcanzó a participar mayormente y el otro, a un dirigente de Revolución Kallejera, quien en la última etapa acompañó al grupo en sus rutas nocturnas, difundiendo la invitación a participar de la organización que los representaba políticamente.

\section{Dimensiones relevantes}

Como grupo, se recorrió por las noches las calles de la ciudad de Santiago, saliendo al encuentro de sus pares, dispuestos a compartir palabras y experiencias. No obstante, esta experiencia resultó singular para cada uno de los participantes, pues mientras para los profesionales se vivía como novedad, para el resto, significaba un nuevo episodio de su estrecha relación con la calle. En concordancia con la diversidad propia de la situación de calle, las relaciones de cada integrante del grupo con la vía pública eran diversas, y particularmente, en el momento de comenzar a participar de esta actividad.

Específicamente, en el momento de incorporarse al grupo, "El Corbata"," tenía 45 años y pernoctaba regularmente en la vía pública, acompañado sólo de sus perros. En el Parque de los Reyes, en la frontera de la comuna de Santiago Centro con Renca, reconocía su hogar. Ahí, a orillas del Río Mapocho, declara convincentemente ser feliz con su vida de calle y no tener aspiraciones de dejarla. Por lo demás, declaraba encontrarse "en paz", pues las actividades delictivas ya no eran su estrategia de supervivencia, sino que vivía "tranquilo y sin molestar a nadie" mediante la mendicidad. Así, decía que la delincuencia era parte del pasado y por lo demás, ya había "pagado" por ella. Con histrionismo y desarrapada apariencia, manifestaba estar en otra etapa de su vida, donde disfrutaba de la libertad de manera más "madura" y piola" (tranquila). Por otro lado, de su familia no

\footnotetext{
11 Las identidades de estas personas se han resguardado y sus nombres o apodos (en el caso de hacerse llamar por alguno) son ficticios.
} 
hablaba. Decía que no le gustaba contar "sus dramas" y que él venía a "otra cosa", en definitiva, a compartir "cosas positivas". De hecho, él se declaraba el autor de la idea de visitar a sus pares, pues tenía ganas de hacer algo novedoso y "positivo".

La situación de Myriam era bastante distinta. A sus 55 años, junto a su ahijado ciego, era desalojada del departamento que habitaba. Efectivamente, esta experiencia adversa no era nueva en su vida, pero la encontraba injusta al reconocerse como una persona trabajadora y esforzada. Sin embargo, no se mostraba derrotada por aquella vicisitud, sino bastante positiva y proactiva en la consecución de apoyo material para revertirla, y en términos de apoyo emocional, protagonizaba -ni más ni menos que- la creación de este grupo. Con una trayectoria vital de gran inestabilidad, malas experiencias de pareja, con un hijo con serios problemas de consumo de drogas y recientemente desalojada, reconocía no perder el gusto por la vida e identificar el sentido de ésta en el acto de compartir. Este carácter optimista y su nivel de liderazgo, da cuenta de los atributos que la llevaron a constituirse, meses antes de la conformación del grupo, como una de las representantes regionales de personas en situación de calle en una cita con los parlamentarios en el Congreso Nacional.

Alejandra, al igual que "El Corbata", pernoctaba regularmente en la vía pública, pero a pasos de la otra orilla del Río Mapocho. A sus tempranos 19 años, no conocía a nadie en la ciudad más que a la estrellas de la televisión que veía pasar por las afueras de Televisión Nacional de Chile, donde ella pasaba las noches. Con sus "familiares" y "amistades" viviendo en lugares alejados e incluso en otras ciudades, Alejandra se encontraba descarnadamente sola viviendo en las afueras del canal de televisión más importante del país. Con una profunda timidez, se manifestaba partidaria de visitar a sus pares por las noches, no obstante, reconocía sentirse intimidada por la calle y en efecto, expresaba que en las afueras del canal era el lugar donde se sentía menos insegura en la calle. Hasta el momento de formar el grupo, el único nexo que Alejandra tenía con la sociedad santiaguina era su soslayado y efímero contacto con las estrellas televisivas y su esporádica comunicación telefónica con sus seres queridos; algunos en la periferia de la ciudad.

Pedro y Juan, no se conocían pero tenían bastantes aspectos en común. Comenzando la tercera década de sus vidas, ya tenían pareja y dos hijos, sin embargo, ninguna estabilidad respecto a sus oficios y domicilios. Ellos y sus familias recurrían a servicios sociales y en particular a los apoyos que otorga el Hogar de Cristo a adultos en situación de calle, no obstante, parte de sus ingresos la conseguían mediante actividades de comercio ambulante, o como cargadores o "pionetas" en la vega (mercado). Así también los dos tenían trayectorias como niños en situación de calle, pero por cierto, también presentan grandes diferencias. 
Pedro, a diferencia de Juan, tenía gran inestabilidad con su pareja y reiterados episodios de violencia, a lo cual se le sumaban sus continuas "recaídas" en el consumo de pasta base de cocaína. No obstante, este complicado "perfil" no impedía que Pedro fuese uno de los miembros con mayor iniciativa y protagonismo en cada una de las actividades realizadas. En efecto, en este periodo, su participación en el grupo coincide con una participación también protagónica de su pareja en otro grupo de personas en situación de calle, que a diferencia de éste, apuntaba al micro emprendimiento. Por su parte, Juan tenía una vida de pareja más estable y a pesar de haber pertenecido a una de las principales caletas $^{12}$ de la ciudad, como niño en situación de calle, no presentaba mayores problemas de consumo. Uno de los principales problemas de Juan era una grabe lesión que tenía en una de sus piernas, la cual le dificulta el caminar y realizar determinadas labores. Sin embargo, esta dificultad, así como sus continuas gripes, no mermaba su gran motivación por salir cada semana a visitar durante las noches a sus pares.

Rosa, al igual que Myriam, asistió al Encuentro en el Congreso Nacional como representante de las mujeres en situación de calle, pero representando, principalmente, a aquellas con problemas de salud mental, que viven en la Hospedería Diferenciada del Hogar de Cristo. Con una trayectoria incipiente de situación de calle y habilidades intelectuales sobresalientes, Rosa participó protagónicamente en numerosas iniciativas de autoafirmación de este colectivo en los años 2005 y 2006. Efectivamente, a instancias de los miembros del grupo, ella se incorpora a fines del primer semestre al grupo y se posiciona como una de las personas más comprometidas, pero a la vez con un agudo sentido crítico dentro grupo. Por lo demás, su simpatía, así como el trato cálido y "educado" que tenía con el resto, le aportaban positivamente a las interrelaciones grupales y a su "llegada" con las personas visitadas. Por su parte, el tratamiento antisicótico que seguía no constituía un motivo de exclusión dentro del grupo ni con las personas visitadas, sino que ella se incorporaba como una persona con una particularidad más, dentro de aquellas que se avizoraban al interior del grupo.

Félix, uno de los miembros fundadores del grupo, reorganizaba su vida luego de superar sus problemas de consumo de alcohol, en el momento de ingresar a éste. Con 45 años y un trabajo estable de maestro de cocina, diariamente recurría al Hogar de Cristo para utilizar la ducha y partir con impecable aspecto a sus labores. De gran profundidad reflexiva y sensibilidad frente a los problemas del resto, Félix contribuyó a delinear inicialmente los objetivos del grupo. Su cordialidad y seriedad en el trato, le imprimieron relevancia a cada detalle de la planificación grupal. Así también, con gran apertura, compartía sus experiencias $y$, en un grupo con liderazgos compartidos, comenzaba a

\footnotetext{
${ }^{12}$ Caleta hace referencia a un grupo de niños o adolescentes en situación de calle que viven juntos. Y Juan años atrás había sido parte de la Caleta del Parque O`Higgins, ubicada en el centro de Santiago.
} 
situarse como uno de los principales lideres de opinión, sin necesidad de mayores aspavientos. Con tales cualidades, no era de extrañar que Félix se ganara fácilmente el respeto y aprecio del resto de los miembros. Si bien no alcanzó a realizar rutas nocturnas, aportó importantes ideas en el momento de la génesis, como posteriormente, sentido de grupo frente a la tragedia de su accidente, la hospitalización y su posterior desaparición.

Lalo, de 35 años, se incorporó en el último cuatrimestre a las rutas nocturnas del grupo. Con una extensa trayectoria en situación de calle y experiencia okupa, contaba con gran conocimiento y reconocimiento de la calle. Como líder de Revolución Kallejera, la promisoria organización de personas en situación de calle y por ende, representante público de los mismos miembros del grupo, participó invitado por ellos al "trabajo nocturno". Lalo se incorporó a las rutas nocturnas para divulgar la invitación a participar de la organización, precisamente, en un momento que la política pública para personas en situación de calle se diseñaba y negociaba, específicamente, en una mesa técnica nacional donde Revolución Kallejera había ganado un puesto. Su participación contagió al resto del grupo en la causa y la actividad nocturna comenzó en esta etapa a moverse en dos arenas, por un lado, en la labor política que todos comenzaron a realizar y por otro, en el diálogo desinteresado que movilizaba originalmente al grupo. Ciertamente, esta dualidad que generó la presencia de Lalo, en ciertos casos parecía situar una de estas labores por sobre la otra, no obstante, de esto sólo nos percatábamos los "observadores", mientras que el resto la realizaban como si las dos se sintetizaran en una o, simplemente, convergieran hacia la misma dirección. Efectivamente, quien se había incorporado era parte de ellos mismos y la invitación que el grupo le hizo, así como la invitación que ahora ellos difundían (que la mayoría de las veces devenía en diálogo), clarificó y potenció el objetivo que el mismo grupo se había propuesto inicialmente: aproximarse a sus pares en una experiencia de reconocimiento, como sujetos válidos y capaces de transformar comunicativamente la realidad social y sus propias vidas.

Si bien, en el último cuatrimestre, el grupo cambió con este nuevo convidado en las salidas nocturnas, diversos son los factores que confluyeron en la etapa final. La psicóloga dejaba de participar en el grupo, se concretaban proyectos individuales tales como la integración al mundo laboral de "el Corbata", Miryam y Juan, como también nuevas dinámicas relacionales entre algunos miembros. Estos cambios individuales, patentemente, generaban cambios a nivel grupal. Reconociendo que la llegada de Lalo no desorienta al grupo, sino que clarifica su sentido inicial y actualiza el compromiso de los miembros, resulta pertinente dar cuenta de determinados aspectos, que tanto antes como después de su llegada, se evidenciaron como lo propio de este "trabajo grupal". Así el sustrato mismo del grupo, en su devenir intersubjetivo, se puede describir en las siguientes dimensiones. 


\section{Reconocimiento de sí mismos como sujetos y ciudadanos}

\section{"Derechos-Ciudadanía"}

Efectivamente, estas personas en situación de calle, desde la conformación del grupo, se orientan a sus derechos y a la ampliación de los límites de su ciudadanía formal hacia una sustantiva (Bottomore 1998), interpelando al Estado y la Sociedad Civil. ${ }^{13}$ Se manifiestan "aburridos", por un lado, "de los atropellos" por parte de las agencias de orden y control y, por otro, de su invisibilidad social, expresada en la indiferencia que recibían por parte el resto de la sociedad y el Estado. Se declaraban "aburridos" de que los ignoraran o simplemente los trataran como "lo peor de lo peor". Con ganas de revertir esta condición deciden acercarse con un buen trato a sus pares y con total respeto y atención, remendar el abandono y soledad en que ellos se encuentran. Al conformarse el grupo, ellos prefirieron visitar a sus pares que realizar ciertas actividades recreativas que la Fundación Hogar de Cristo estaba dispuesta a financiar. En última instancia, ellos sitúan como máxima prioridad del grupo validar a sus pares como ciudadanos, orientándose a reconocer sus derechos y reparar su abandono y soledad participando de la sociedad como espacio de encuentro. No obstante, lo que aquí se revela es la absoluta claridad sobre su propia experiencia de vida en calle, donde la vulneración de derechos y la indiferencia recibida por parte del resto, se contrapone a las habilidades comunicativas y sociales que reconocen en sí mismos como sujetos. En definitiva, ellos se plantean validar en sus pares las singularidades que reconocen en sí mismos, pero que son negadas e ignoradas sistemáticamente por "los incluidos". En efecto, destacan que tanto ellos como sus pares tienen mucho que decir y se deciden a ir a escucharlos, a dialogar y reflexionar en conjunto.

En consonancia con las experiencias vividas por su colectivo durante el año anterior $^{14}$ y el empoderamiento evidenciado en Revolución Kallejera, deciden "tomarse la calle de una manera diferente", destacando que son actores reflexivos y capaces de impulsar cambios. Se proponen iluminar con palabras y diálogo lo invisible. Reivindican la calle como un espacio social, donde no sólo se transita o duerme, sino además se piensa, anhela y construye una sociedad diferente. Efectivamente, viven un proceso donde se comienzan a desenvolver con mayor seguridad de sí mismos, donde protagonizando una experiencia social transformadora -a pesar de su profunda exclusión- se reconocen como

\footnotetext{
${ }^{13}$ Significativos fueron los logros alcanzados por este colectivo durante los años 2005-2006. Organizarse políticamente, contar un tercer sector aliado y un Estado receptivo a sus inquietudes, les permitió alcanzar nuevos derechos sociales (incorporación al Sistema de Protección Chile Solidario), políticos (participación en el diseño de la política pública e interlocución directa con autoridades de gobierno y político-partidarias) y civiles (legitimación pública de su organización y demandas, y determinados acuerdos con las autoridades respecto al resguardo frente a los atropellos históricamente recibidos).

14 Las organizaciones que trabajan con personas en situación de calle le llamaron al año 2005 "El año del Pueblo en Calle", en virtud de las diversas actividades que esta población protagonizó públicamente y por la visibilización social que así alcanzaban.
} 
$\operatorname{ciudadanos}^{15}$ y parte de la sociedad. La autoafirmación intersubjetiva de sus singularidades, sin ser una apología de la calle como hábitat idóneo, potenció su identidad como validación de sus propias capacidades y experiencias vitales. Volviendo a confiar en los otros, aumentaron su propia confianza en sus capacidades y el orgullo de ser quienes eran.

\section{De sí mismos como actores transformadores}

\section{"Transformadores de su entorno"}

De tal manera, apelando a su ciudadanía, reivindican su pleno derecho a transformar la calle en un lugar de encuentro e inclusión. No quieren "dar lástima", sino aportar desde sus experiencias en la construcción de una sociedad más solidaria y respetuosa de la diversidad. En última instancia, se orientaban hacía un principio amplio de ciudadanía que reconoce las singularidades, sin necesidad de establecerse diferencias que determinen la presencia de ciudadanos plenos y ciudadanos de segunda categoría (Jenson \& Phillips 1999).

Tanto en el diálogo desinteresado con sus pares, como en la invitación política que difundían, ellos apuntaban a transformar -con afecto, respeto y diálogo- la faz de un ambiente que se asocia a la hostilidad y la enajenación humana. Concientes de que en la calle no sólo hay arbitrariedad en las relaciones humanas, sino en muchos casos -lo que sociológicamente se entiende como- una genuina acción comunicativa, el grupo se propuso potenciar, visibilizar y propagar estas prácticas en que el reconocimiento del otro y las pretensiones de validez se constituyen como los criterios relacionales. Relevando así la calle como lugar público, pasando de lo escondido a lo compartido, se restaba espacio a las arbitrariedades y atropellos que se vivencian en ciertos rincones oscuros y olvidados. Pues por excelencia la acción comunicativa, como alternativa emancipadora de las arbitrariedades del poder, se potencia en lugares abiertos y luminosos donde se pueden congregar las diversas subjetividades.

\section{"Transformadores de sus propias vidas"}

Reiteradamente, mientras participaban, decían que la actividad los motivaba por hacerlos sentir "responsables" y por brindarles un "desahogo" de sus rutinas diarias. No obstante, las actividades del grupo tenían para ellos un sentido en sí mismas, que no sólo se limitaba a estos aspectos básicos. Sus vidas se transformaban en la relación con sus pares.

\footnotetext{
15 Efectivamente, ciudadanos plenos no son, pero evidentemente, "toda aspiración reconstructiva de los ideales de ciudadanía debe partir del reconocimiento de su heterogeneidad semántica y de su connotación de constructo social. Es decir, la lucha por la ciudadanía es acción cotidiana permanente, espacio de conflicto y antagonismo social. La ciudadanía plena es la utopía y, como se sabe, nadie ha encontrado la isla de los sueños de Moro" (Sojo 2002: 37).
} 
"Uno se conoce más a sí mismo visitando gente...uno se refleja", declaraban en la profundidad de la reflexión grupal. El familiar desgarro del otro, que se reflejaría en sus propias conciencias -como fenómeno apresentativo- efectivamente suscitó cuestionamientos y cambios en sus propias vidas. La experiencia intersubjetiva en que se difuminan las mediaciones entre el yo y el nosotros, concretamente abrió espacio de "auto evaluación" de la situación propia. Como un proceso de toma de conciencia, no se hizo esperar la proyección al cambio por parte de los miembros del grupo. "Uno no puede seguir en la misma 'pará', si estamos haciendo este trabajo", declaró "el Corbata" cuando llegó a una reunión acicalado, con trabajo y hablando de lo grande que estaban sus hijas.

Y específicamente en esta actividad diferente en sus rutinas cotidianas, que ellos catalogaban como "el trabajo", se transformaban, se trabajaban a sí mismos. La "toma de conciencia" que desarrollaron respondía, por un lado, a la experiencia intersubjetiva con sus pares, pero, por otro, al hecho de embarcarse en una labor distinta, en que lo dado se trastocaba. Así se cumplía aquella idea hegeliana, "de que la conciencia únicamente puede adquirir nuevas perspectivas y acercarse a comprender su propia realidad si era capaz de embarcarse en una praxis diferente" (Vallejos, Ortí \& Agudo 2007: 311). En un fenómeno similar a lo descrito por Hegel como desdoblamiento de la conciencia, en este obrar la razón, o más bien el espíritu, "se encuentra con el espíritu" (Hegel: 1985: 407). En el mismo obrar del grupo, la individualidad de estas personas se realizaba, ya que, en el amplio sentido, "la conciencia que trabaja llega, pues, de este modo a la intuición del ser independiente como de sí misma" (Hegel 1985: 120). Y esta autoconciencia, que emanando al mismo tiempo de este obrar se refleja en sí (Hegel 1985: 190), por lo demás, se potenciaba en un flujo de experiencia común, en la intersubjetividad. "Es que con esta actividad uno ve la realidad más allá", decía Pedro, por su parte. Era evidente como cada uno de los participantes del grupo, incluidos los investigadores, "nos sentimos orgullosos, nos sentimos otras personas", como declaraba Rosa. Y es que efectivamente, en lo más cotidiano sus vidas cambiaban. Unos se revinculaban con sus familias, otros se consolidaban en los puestos de trabajo conseguidos o, simplemente, hacían nuevos amigos, sus anhelos eran otros y en sus mentes rondaban, con mayor insistencia, determinadas inquietudes. "Llego con nuevas ideas y uno reflexiona caleta (bastante)... (esta actividad) me ha dado temas de conversación con mi pareja", contaba Juan en una de las reuniones evaluativos del grupo.

Muchos eran los cambios en sus vidas cotidianas, unos emergían con espontaneidad y otros directamente respondían a ciertos desafíos que, sin ser explícitos, la misma participación en esta actividad implicaba. Si bien la recepción era muy positiva por la gente visitada, necesitaban no sólo ser validados por sus pares, sino también por sí mismos en una actividad en que ellos cumplían un nuevo "rol" social. Necesitaban en definitiva, dar un paso hacia la transformación de sus vidas, para sentirse legítimos frente a sí mismos, en el fondo, convencerse a sí mismos. Efectivamente, en ocasiones no se creían a sí mismos 
dando mensajes desde la miseria personal. Les gustaba lo que recibían, pero no se quedaban conformes con lo que transmitían. "El Corbata", quien se reconocía más arraigado a la calle, fue el primero en reconocer esta necesidad personal de cambio. Reconoció que no podía "seguir en la misma de la gente que estamos visitando", y se propuso conjugar esta actividad nueva con una vida personal también nueva. En efecto, "el Corbata" no sólo se consolidó en su trabajo formal, reestableció contacto con sus hijas y dejó la callé, sino que además volvió a hacerse llamar por su verdadero nombre: Samuel. ${ }^{16}$

\section{Reconocimiento del otro como igual y diferente}

\section{"Respeto"}

El respeto por el otro fue una tónica en las actividades grupales. Desde la primera reunión -donde todos se escucharon con atención, contrastando y compartieron ideas- y la primera visita a la calle -donde se ganaron en el diálogo la respuesta atenta de las personas visitadas - el grupo basó sus relaciones y actividades en el respeto por el otro. No resultaba necesario intervenir por parte de los profesionales, sino que, en las escasas ocasiones en que parecía necesario, entre ellos emergieron mociones de orden. Como por ejemplo, cuando en el tercer cuatrimestre Pedro "se desordenó" con el uso de la radio del furgón. En la reunión diurna esta situación fue analizada por el grupo, a instancias de Miryam y Juan, y finalmente se decidió "dejar de pelusear", como ellos le decían al desorden y la "chacota".

Una de las situaciones que asombraba, fue la ausencia de pugnas explícitas por el liderazgo. El carácter horizontal de la participación, donde todos cumplían roles relevantes y singulares, no daba espacio a conflictos por el liderazgo o a los denominados conflictos de "egos". Ciertamente, esto podría ser explicado por el deterioro psicosocial, y en específico, de la autoestima, que desarrollan estas personas, no obstante, la horizontalidad de las relaciones y el sentido de grupo no hacían necesitar mayor protagonismo que el compartido.

Si bien Samuel solía interrumpir al resto en las reuniones y Alejandra era tímida, en general, todos se mostraban a gusto tanto escuchándose como "tomando la palabra". Disfrutaban de la acción comunicativa en condiciones de simetría. "Es bonito comunicarse con otra gente y sobre todo de la calle", decía Juan. De hecho, aunque nunca se aplicó y la idea era visitar a la gente con las manos vacías, Samuel intentó incorporar a las salidas nocturnas una dinámica carcelaria como "la ronda de mate", donde el encuentro se basa en conversar y compartir aquella bebida, en un clima de respeto por el otro y los turnos correspondientes. La idea era apoyada por el resto del grupo, y en efecto, él compró un

\footnotetext{
${ }^{16}$ Así se le llamará aquí para resguardar su identidad.
} 
paquete de hierba mate que lo llevó a una reunión, sin embargo, por olvido no se practicó finalmente. Con todo, el grupo, efectivamente, ponía en el centro de su actividad la experiencia dialógica.

\section{"Empatía"}

Sorprendentemente, la primera visita a la calle se caracterizó por el encuentro de ellos con personas que hace bastante tiempo no veían. Particularmente, Pedro se encontró con alguien de quien jamás pensó recibir una tan buena acogida. "El Tito", un ex locutor radial de aproximadamente 60 años, que en otra época había sido violentado sistemáticamente por Pedro, tuvo una indulgente reacción frente al nuevo acercamiento de su ex victimario. Luego que Pedro compartió con todo el grupo de personas el pasado común que tenían y le explicase que ahora "andaba en entra actitud", "el Tito" le respondió: "en otra época quisiste ser amigo mío a la fuerza, obligándome a consumir, ahora puedes serlo sin necesitad de violencia ni de alcohol".

Con la ventaja de contar con una experiencia común como la situación calle, por un lado, la necesidad de reconocimiento de las personas visitadas había sido bien identificada por el grupo y, por otro, su novedosa propuesta -alejada de la caridad- era fácilmente interpretada por ellas. Las personas reaccionaban positivamente a la iniciativa del grupo y no hacía falta explicar en detalle el propósito de las visitas y la ausencia de obsequios, lo que efectivamente, evidenciaba que eran parte de un mismo flujo de experiencia. En efecto, luego de escucharlos durante un rato, "el Tito" les dijo en su primera visita: "ah, entonces, ustedes son un grupo comunicacional". Recibimientos tan positivos y de tanta cercanía como éste, que no ameritaba grandes explicaciones de la labor del grupo, fortalecían continuamente la identidad del grupo y actualizaban sus objetivos.

Ciertamente, se daba una propensión a la empatía entre estas personas. En efecto, sus competencias comunicativas eran suficientes para orientarse al entendimiento, pero, por otra parte, la familiaridad con que se experimentaba al otro era decisiva. Aunque en reiteradas ocasiones fueron constructivamente críticos al interior del grupo, muy rara vez reprochan o juzgaban la situación del otro. Demostraban una actitud comprensiva entre sí sobre todo frente a las dificultades que les tocaba vivir- y con las personas visitadas. Cuando en la calle se encontraban con personas en crisis o aflicción eran capaces de actuar acogedora y cariñosamente, guardando sus impresiones o cuestionamientos para otro momento, cuando la otra persona estuviese en condiciones de dialogar. No tendían a ofrecerles soluciones o grandes consejos a las personas, sino más bien, reconociéndolos como sujetos legítimos, dialogaban y reflexionaban conjuntamente.

\section{"Solidaridad"}

Este grupo, por cierto, se inicia con un espíritu marcadamente solidario. Cuando se proponen visitar a sus pares, subyace la pretensión de aliviar el abandono y soledad en que 
estarían inmersos. Priorizando esta actividad frente a posibles actividades recreativas, reconocen, por un lado, como un deber acordarse de sus pares, pero por otro, la mayor gratificación personal en esta actividad altruista. Si bien son concientes de que en estas visitas habrá un intercambio de beneficios, diciendo que ellos también quieren aprender de los otros, no se evidencia ninguna preocupación sobre cuánto llegará a ser el beneficio propio. Como población excluida y pobre, sus trayectorias vitales están delineadas por experiencias solidarias en la cotidianeidad, de modo que esta actividad altruista gozaría de gratuidad y espontaneidad frente a quienes identifican como pares. Este grupo mostró que frente a personas que vivencian sus mismas dificultades y vulneración de derechos, se sobreentienden "las devueltas de mano" o retribuciones, al nivel de omitir toda referencia o tematización de ellas. En este grupo se vivía con profunda gratuidad cada una de las actividades desarrolladas.

Al interior del grupo se evidenciaron numerosas experiencias de solidaridad. Los vínculos entre sí se potenciaron casi instantáneamente en el momento de comenzar a participar. No sólo solidarizaron como compañeros de labores, sino como personas altamente significativas entre sí. Expresión de esto es que muchos comenzaron a vivir juntos y Samuel le consiguió trabajo a Miryam en la misma empresa de aseo público en donde el trabajaba. Un episodio concreto de solidaridad interna que, por cierto, marcó al grupo fue el accidente de Félix. Cuando Félix fue hospitalizado recibió las visitas espontáneas de sus recién conocidos compañeros de grupo y posteriormente, cuando dejó el hospital y desapareció, fue buscado personal y grupalmente, durante todo el primer semestre, por los lugares que él frecuentaba. Lamentablemente, el grupo estaba inmerso en una gran metrópolis donde la gente puede perderse y dejarse de ver con sus seres queridos, nos obstante, en esta nueva actividad algunos se reencontraban.

Miryam destacaba por su espíritu solidario. En efecto, era conocida extendidamente en la calle como "la Mami", por el gran cariño que suscitaba entre la gente. Lo cual se evidenció en la primera visita, cuando una mujer de 30 años aproximadamente agradeció emocionada al grupo por haberle traído a "la Mami" que había dejado de ver hace años.

Miryam y Rosa, las dos mayores del grupo, se caracterizaban por aportar al grupo un cariz afectuoso en la aproximación a las personas visitadas. Por ejemplo, en una oportunidad el grupo se encontró con una pareja que discutía, la mujer lloraba desconsolada y no había claridad sobre qué hacer. El grupo discutió para tomar una decisión, pues los hombres se inclinaban a escarmentar al supuesto maltratador, mientras que las mujeres proponían aproximarse cálida y acogedoramente. El grupo se inclinó finalmente por la segunda alternativa y Myriam protagonizó un genuino acto de acogida y contención de la mujer acongojada. El grupo rescató como un ejemplo a seguir la actitud de Miryam, y fortaleció la convicción de acercarse respetuosa y afectuosamente a sus pares, revirtiendo así los malos tratos que en lo cotidiano reciben. 
Con tales aspectos, identificados como esenciales y constitutivos del grupo, resulta evidente que la convocatoria que éste comienza a realizar en el último semestre, para que sus pares se sumen a Revolución Kallejera, no desvirtúa sus iniciales objetivos, sino más bien los potencia. La reivindicación de sí mismos y de sus pares como sujetos, es consustancial a la labor constante del grupo. Las visitas a sus pares y la convocatoria que comienzan a difundir, no apuntan sino a la misma causa: la validación de su condición de ciudadanos y sus capacidades como actores transformadores. Efectivamente, el grupo al invitar a Lalo, no sólo evidencia el aprecio por su persona, sino que ratifica el objetivo reivindicativo que había asumido desde un inicio, en concordancia con los procesos de autoafirmación desarrollados en este período por el amplio colectivo de personas en situación de calle.

Por lo demás, en estas dimensiones descritas, se identifican aspectos relacionales que potencian la cercanía e identificación entre las personas en situación de calle. Más allá del reconocimiento social encarnado en la ciudadanía, estas personas desarrollan un sentido de pertenencia y mancomunión que daría pie a su constitución como sujetos. La proximidad con que experimentan al otro, suscita maneras de relacionarse propicias para la constitución de sí mismas como actores colectivos y principales protagonistas de la construcción de su ciudadanía.

\section{Conclusiones}

Este grupo se componía de personas con distintas trayectorias de calle y por lo tanto, con diversos niveles de autosuficiencia y deterioro psicosocial (Rojas Pedemonte 2007). Por no tratarse de una investigación cuantitativa, las experiencias aquí descritas no son generalizables al total del colectivo. En este mismo sentido, favorablemente las dificultades y problemas que se presentaron tampoco podrían ser proyectadas a futuras experiencias similares. No obstante, resulta pertinente hacer referencia a ellas.

Las dificultades fueron las propias de una actividad sin precedentes, de diseño flexible y participación horizontal. En ocasiones, estas actividades se basaban bastante en la improvisación y el ingenio de los miembros, pero se generaba cierta incertidumbre. La horizontalidad y la falta de claridad respecto a las responsabilidades, provocaba niveles de desorganización que en dos ocasiones puntuales dificultaron la realización de las actividades. Sin embargo, cuando se identificaban dificultades, como por ejemplo, en la planificación de las rutas, se acordaban soluciones. Buscaban siempre alternativas y a cada encuentro llegaban con ideas nuevas para el grupo.

Como es de esperar, los procesos de inclusión que ellos comenzaron a desarrollar con el tiempo comenzaron a dificultar su participación de las actividades. Pues por ejemplo, rutinas laborales o nuevas actividades con sus personas significativas (familiares, nuevas amistades, parejas, etc.), podían coincidir con las reuniones o rutas nocturnas. Así, aunque 
en oportunidades se ausentaban y luego retomaban su participación, el grupo se veía disminuido cuando no se contaba con algunos de ellos. ${ }^{17}$

Con lazos que se habían estrechado extremadamente, como por ejemplo, llegando a vivir o trabajar juntos, las relaciones entre los miembros comenzaron a responder también a aspectos externos al grupo. Conjugándose esto con la ausencia -durante el último cuatrimestre- de un acompañamiento personalizado como el realizado por la psicóloga, se desajustó la dinámica grupal, en alguna medida. Favorablemente, el compromiso grupal no decayó, pero aparecieron ciertos conflictos. Ejemplo de esto es el conflicto que tuvieron Pedro y Juan, con sus familias de por medio. Luego de este conflicto, el grupo completo se reunió, incluidos ellos, y se acordó que Pedro se retiraría ante su negativa a compartir con Juan. Por cierto, la estrechez de los vínculos alcanzados impulsaba, como en todo grupo social, conflictos. Y además, los problemas se propician cuando estas personas cuentan, prácticamente, con dos alternativas: vivir solos o hacinados. Así, reconociendo lo inevitable que son estos conflictos en relaciones próximas, la presencia de un profesional de la psicología resulta idónea para sacar -interdisciplinariamente- el máximo provecho a la positiva disposición al diálogo y al entendimiento que estas personas han demostrado tener.

Junto a estas dificultades, esta investigación ha develado significativas oportunidades en las posibilidades de avanzar en la autorfirmación de personas excluidas y en la construcción de su ciudadanía. En gran medida ha quedado en evidencia el elevado nivel de impacto que puede alcanzar una actividad grupal como ésta, donde son las mismas personas en situación de calle las que se intervienen intersubjetivamente. En esta suerte de intervención no forzosa y participativa, basada en una actividad para otros, personas con historias de fracaso en intervenciones tradicionales, cambiaron significativamente sus vidas cotidianas. Juan, Samuel y Miryam consiguieron trabajos estables y "mejoraron", según sus propias palabras, las relaciones con sus familias $\mathrm{u}$ otros significativos. La radical transformación que desarrolló "el Corbata" o Samuel, significó a tal nivel una autoafirmación de sí, que revinculado con su familia, con residencia y trabajo estable, decidió finalmente dejar de participar en el grupo, pues la calle para él "era", es decir, la consideraba como una "etapa superada". "Es un bonito recuerdo el grupo, pero estoy en otra...ahora quiero dar vuelta la página", confesó luego de un año de participación en esta iniciativa de la que el mismo se sentía propulsor.

Durante el proceso vivido, efectivamente, se construyen personalidades más seguras de sí mismas y orgullosas de sus singularidades. Ciertamente, el orgullo que significaba en ellas estar embarcadas en una actividad diferente, cambió sus auto-percepciones. Se

\footnotetext{
${ }^{17}$ Posiblemente, habría resultado óptimo que el grupo se hubiese compuesto por ocho personas en situación de calle, para evitar estas situaciones en que coincidían algunos ausentándose el mismo día.
} 
reconocieron a sí mismas en una práctica considerada por ellas y sus pares como positiva. El orgullo que significa realizar este trabajo voluntario, las hacía sentirse -a la vez- actores capaces y dignos, es decir, válidos demandantes y titulares de nuevos derechos. De hecho, a muchas personas les contaban de su actividad y a sus mismos pares les prometían visitarlos. Mientras evaluaba los posibles lugares para visitar en las rutas, Samuel les decía a los suyos: "un día de estos me dejaré caer por aquí con unos amigos también de la calle...". El significado que ellos le atribuían al "trabajo" del grupo no es mensurable. Nunca cuestionaron el sentido de salir a visitar a sus pares; es más, declaraban encontrarle un valor en sí a las salidas, y que, precisamente éstas eran lo más importante del grupo. Ciertamente, el sentido que ellos identificaban en las visitas contrarrestaba las dificultades interpersonales y las falencias organizativas que muchas veces ocurrían. Pudiendo estar enojados entre sí o molestos por ciertos traspiés del grupo, las personas de igual modo asistían y ratificaban su compromiso semana a semana. En sus propias palabras se refieren a sus inasistencias o inconstancias en la participación: "uno cae pero siguen saliendo". En efecto, cuando se terminó el período planificado de actividades del grupo, cuatro de sus seis miembros ${ }^{18}$ más Lalo, insistentemente manifestaron su deseo de continuar participando.

Considerando que esta iniciativa respondió a una investigación-acción participación, es oportuno referirse a los aspectos en que las personas en situación de calle fueron capaces de enseñar al investigador. Por cierto, el saber popular tiene mucho que aportar a las ciencias sociales y a todos aquellos que se propongan generar cambios en la realidad social. Específicamente, aquellos interesados en trabajar en temáticas de exclusión, deben reconocer que son las mismas personas que la vivencian quienes cuentan con la interpretación más directa y privilegiada de sus propias experiencias. Por cierto, esto parece de perogrullo, pero las perspectivas radicales del estructuralismo -de amplia difusión en las ciencias sociales- se niegan a reconocer las capacidades transformadoras e intelectivas de los sujetos. En esta oportunidad resulta imposible adherirse a estas perspectivas y desconocer lo que las personas en situación de calle han demostrado como actores sociales y fuentes directas de información e interpretación acerca de sus experiencias.

Comenzando por aspectos concretos, el manejo o conocimiento que pueden llegar a tener de la ciudad y sus dinámicas, cualquier urbanista o sociólogo urbano lo quisiera. La capacidad para identificar riesgos en situaciones que aparentan no tenerlo o reconocer oportunidades en la calle, dan cuenta del desarrollo de habilidades que la misma experiencia les ha otorgado. Son capaces de distinguir características en sus pares que, sin ser evidente, indican información relevante sobre sus disposiciones o intensiones.

\footnotetext{
${ }^{18}$ Es importante recordar que Samuel dejó de participar luego de comenzar un proceso de inclusión social y Pedro, manifestando sus deseos de seguir participando, no lo hizo sólo en vista de su problema con Juan.
} 
Ciertamente, estos aspectos asombraban a los voluntarios que pudieron participar de las rutas, pues -teniendo experiencia de "trabajo en calle"- se reconocían como neófitos frente a los verdaderos expertos. El conocimiento que tenían de calles y lugares recónditos jamás visitados por los voluntarios, asombraba. No obstante, lo que resultaba más llamativo era que no recurrían a mayores aspavientos ni a dádivas para conseguir una buena recepción de sus pares, sino más bien, se ganaban una buena acogida siendo profundamente cálidos y comunicativos en el trato. Tal como lo reconocieron los voluntarios participantes, "hay mucho que aprender de ellos" y todo voluntario o profesional vinculado a la temática debiese conocer cómo se relacionan entre sí en experiencias como éstas, donde más importante que la comida o el abrigo llevado, puede resultar la comunicación en el momento de la visita.

Por lo demás, no sólo los voluntarios pueden aprender de ellos, sino todo el resto de la sociedad. Pues su reivindicación, efectivamente, interpelaba a todos los sectores sociales. En este caso, se estaría frente a una población que reclama legítimamente su reconocimiento social. Concretamente, se tomaron la calle, y no sólo en sus nuevos trabajos en los servicios de aseo público, sino en su legítima pretensión de hacer de ésta un espacio de ejercicio de la ciudadanía, es decir un lugar de reconocimiento de sujetos diversos y titulares de derechos.

Aunque generalmente se cree que la "flecha de la causalidad va de los derechos a la identidad" (Jenson y Phillips 1999: 99), estas personas, sin necesidad de esperar a ser reconocidos ya como ciudadanos plenos, se identifican a sí mismos como actores constitutivos y constituyentes de una sociedad que aún no los reconoce del todo. Por cierto, "se trata de actores de algún modo incluidos aunque en forma subordinada, y que se organizan y luchan por evitar la exclusión y por acceder a mejores niveles de vida" (Garretón 2000: 138). Se sienten protagonistas del proceso de constitución de su propia ciudadanía. Como ciudadanos de segunda, no tienen una dócil lealtad o gratitud frente a la comunidad que los incluye (Jenson y Phillips, 1999), pero han desarrollado un sentido de pertenencia nacional previo a su plena ciudadanía, desde el cual se reconocen como agentes de aquel cambio que les concedería plena legitimidad y derechos. Como plantea Marshall (1998), los derechos de ciudadanía podrían alcanzarse en secuencias diversas, y por lo demás, se reconoce que la ciudadanía formal (pertenencia a un Estado Nacional) no es requisito de la ciudadanía sustantiva (participación en la comunidad política, expresada en el conjunto de derechos que, efectivamente, se detentan) y viceversa (Bottomore 1998). No son sólo los limitados derechos que detentan, sino también la exclusión y la ciudadanía sustantiva a la que aspiran, lo que se constituye como experiencia común articuladora. Y en este caso es tanto a la sociedad civil como al Estado donde dirigen los dardos, a quienes interpelan y reconocen como interlocutores.

La construcción de la ciudadanía efectivamente es un proceso intersubjetivo, que se desplegaría como acción comunicativa (Matus 2006) en la medida que reconocemos al otro 
como un interlocutor válido y capaz de modificar -en alguna medida- la sociedad y nuestros propios pareceres desde su singular interpretación de la realidad. De lo contrario, la vida social permanecerá regida por la arbitrariedad de aquellos que gozan de los derechos. Sin embargo, la ciudadanía, favorablemente, se reconstruye en un contexto actual de orientación democrática y global, donde emergen nuevas demandas sociales y las posibilidades de acallarlas son cada vez más remotas. Sin responder a un simple juego de palabras, en este tránsito estas personas excluidas se han comenzado a proyectar legítimamente desde la mera vía pública hacia la esfera pública. Si por años ha sido fácil desatenderlos al caminar por las calles sin mirarlos, ahora no bastará con taparse los ojos frente a los espacios sociales que comienzan a reivindicar para de sí mismos y, por extensión, para el resto de la comunidad. En la modernidad reflexiva, los excluidos -no sólo en Chile, sino a nivel mundial- comienzan a reconocerse como sujetos, sin necesidad de ser reconocidos aún como ciudadanos plenos por la sociedad, sino más bien por la distancia misma que media entre estas categorías y sus desarraigadas experiencias de vida. Sólo reconociéndose a sí mismas y entre sí, como sujetos válidos y demandantes de derechos (Jelin 1993), las personas en situación de calle fueron capaces de apelar con inusitado éxito al Estado y a la Sociedad Civil (incluidas ellas mismas), en pos de la incipiente construcción de su ciudadanía. Sin duda suelen ser largos los procesos de construcción de ciudadanía, no obstante, tienen a su favor la proximidad con que experimentan a sus pares, como un sustento articulador para su constitución en sujetos colectivos. 


\title{
Bibliografía
}

\begin{abstract}
Alonso, L.H. (1997), "La reconstrucción de la solidaridad: La crisis del Estado de Bienestar y los dilemas de la ciudadanía", en Revista Acciones e Investigaciones sociales, $\mathrm{N}^{\circ}$ 6, Universidad de Zaragoza, Zaragoza. Edición electrónica disponible en http://dialnet.unirioja.es/servlet/articulo?codigo=170219 (01-06-2008).
\end{abstract}

Aristóteles (1998), Metafísica, Gredos, Madrid.

Barros, P; de los Ríos, D; Torche, F. (1995), Lecturas sobre la exclusión, IOT, Santiago de Chile.

Beck, U. (1996), "Teoría de la modernización reflexiva”, en Beriain, J. Las consecuencias perversas de la modernidad. Anthropos, Barcelona.

Brenner, N. (2003), "La formación de la ciudad global y el re-escalamiento del espacio del Estado en la Europa Occidental post-fordista”, en EURE v.29 n.86, Santiago de Chile.

Castel, R. (1997), Las Metamorfosis de la Cuestión Social. Una crónica del salariado, Paidós, Buenos Aires.

CEPAL. (2007), Estudio económico de América latina y el Caribe 2006-2007, CEPAL, Santiago de Chile.

Chomsky, N. (2001), Sobre la naturaleza y el lenguaje, Cambridge University Press, Madrid.

Colectivo Ioé, (1993), “Investigación-Acción Participativa. Introducción en España”, en Documentación Social $\mathrm{N}^{\circ}$ 92, Madrid.

Cress, D. \& Snow, D. (1996), "Mobilization at the Margins: Resources, Benefactors, and the Viability of Homeless Social Movement Organizations", en American Sociological Review Vol. 61, No. 6: 1089-1109, Nueva York.

Edgar, B. \& Meert, H. (2005), Fourth Review of Statistics on Homelessness in Europe, FEANTSA, Bruselas.

FEANTSA (2007), Homeless in Europe. Social and Demographic Change and Homelessnes, FEANTSA, Bruselas.

Flecha, R. Et al. (2004), "Metodología comunicativa crítica en la investigación en las ciencias sociales: la investigación Workaló", en Lan Harremanak, Revista de Relaciones Laborales, Bilbao.

Freire. P. (2004), Pedagogía de la autonomía. Saberes necesarios para la práctica educativa, Paz e Terra, Sao Paulo.

Gacitúa, E., Sojo, C. y Davis, S. (Editores), (2000), "Exclusión Social y reducción de la pobreza en América Latina y el Caribe", FLACSO - Banco Mundial, San José, Costa Rica.

García, S. (1996), "Cities and citizenship", en International Journal of Urban and Regional Research, Vol. 20. (1), Blakwell, Oxford.

García, S. \& Lukes, S. (comps.). (1999), Ciudadanía justicia social, identidad y participación, Siglo XXI, Madrid.

García Canclini, N. (1995), Consumidores y ciudadanos. Conflictos multiculturales de la globalización, Grijalbo, D.F. México. 
Garfinkel, H. (1996), “Etnometodology‘s Program”, en Social Psychology Quarterly, Vol. 59, №1: 5-21, New York.

Garretón, M. A. (2002), La sociedad en que vivi(re)mos. Introducción Sociológica al Cambio de Siglo, LOM, Santiago de Chile.

Idem (2000), "Igualdad Ciudadanía y Actores en las políticas sociales", en Reuben Soto, S, Política social: Vínculo entre Estado y Sociedad, FLACSO - Editorial Universidad de Costa Rica, San José de Costa Rica.

Giddens, A. (1998), La constitución de la sociedad. Bases para la teoría de la estructuración, Amorrontu, Buenos Aires.

Habermas, J. (1993a), El discurso filosófico de la modernidad, Taurus, Madrid.

Idem (1993b), La lógica de las ciencias sociales, Red editorial Iberoamericana, México.

Idem (1994), Teoría de la acción comunicativa: complementos y estudios previos, Cátedra, Madrid.

Idem (1999), Teoría de la acción comunicativa, Taurus, Madrid.

Hegel, G.W.F. (1985), La fenomenología del espíritu, Fondo de Cultura Económica, Madrid

Husserl. E. (1985), Meditaciones Cartesiana, Fondo de Cultura Económica, D.F. México.

Ibáñez, J. (1986), "Perspectivas de la investigación social: el diseño en las tres perspectivas” en García Fernando, M; Ibáñez, J. \& Alvira, F. (comps.), El análisis de la realidad social, Alianza, Madrid.

Jelin, E. (1993), “Cómo construir ciudadanía? Una visión desde abajo”, Revista Europea de Estudios Latinoamericanos y del Caribe, $\mathrm{N}^{\mathrm{o}}$ 55, Centro Interuniversitario de Estudios y Documentación Latinoamericanos (CEDLA), Ámsterdam.

Idem (2003), "Citizenship and Alterity: Tensions and Dilemmas", Latin American Perspectives, Vol. 30, No 2, pp. 101-117. Edición electrónica disponible en http://www.jstor.org/stable/3184979 (20-06-2008).

Jenson, J \& Phillips, S. (1999), "De la estabilidad al cambio en el derecho de ciudadanía canadiense”, en García, S. \& Lukes, S. (comps.), Ciudadanía justicia social, identidad y participación, Siglo XXI, Madrid.

Marshall, T. H. \& Bottomore, T. (1998), Ciudadanía y Clase Social, Alianza, Madrid.

Márquez, E. (2006), "Oportunidades y límites en el abordaje teórico de la situación de calle”, en Márquez, E. y Rojas, N. Reflexiones acerca de las personas en situación de calle. Documento de trabajo. Red Calle, Santiago de Chile. Edición electrónica disponible en http://www.redcalle.cl/descripdecla.asp?ImageID=299 (02-09-2007).

Matus, T. (2006), Apuntes sobre Intervención Social. Santiago de Chile. Documento Inédito.

MIDEPLAN (2005), Habitando la calle. Catastro Nacional de Personas en Situación de Calle, Centro de documentación MIDEPLAN, Santiago de Chile.

Moreno Pestaña, J.L. \& Espadas Alcázar, M.A. (1988), "Investigación Participativa”, en Terminología científicosocial: aproximación crítica, Anthropos, Barcelona.

Moulaert, F; Martinelli, F., Gonzalez, S. \& Swyngedouw, E. (2007), "Introduction: Social Innovation and Governance in European Cities: Urban Development Between Path Dependency and Radical Innovation”, en European Urban and Regional Studies, 14: 195-209, Londres. 
Ossa, L. (2005), (Adolescentes) en situación de calle: construcción de identidad en situación de extrema vulnerabilidad. Un acercamiento cualitativo, Tesis para optar al grado de Magíster en Psicología, Universidad de Chile, Santiago de Chile.

Red Calle (2005), Voz y Ciudadanía para las personas en situación de calle. Informe de resultados Asambleas Regionales, Red Calle, Santiago de Chile.

Rodríguez Gabarrón, L. \& Hernández Landa, L. (1994), Investigación acción participativa. Cuadernos Metodológicos, CIS, Madrid.

Rojas Pedemonte, N. (2006), "Personas en Situación de Calle en la perspectiva de la Exclusión y la Vulnerabilidad Social", en Márquez, E. y Rojas, N., Reflexiones acerca de las personas en situación de calle. Documento de trabajo. Red Calle, Santiago de Chile. Edición electrónica disponible en http://www.redcalle.cl/descripdecla.asp?ImageID=299 (02-09-2007).

Idem (2007), Más allá de las carencias. Tipologías de personas en situación de calle, Unidad de Estudios Fundación Hogar de Cristo, Santiago de Chile.

Sabatini, F., Cáceres, G. \& Cerda, J. (2001), "Segregación residencial en las principales ciudades chilenas: Tendencias de las tres últimas décadas y posibles cursos de acción”, EURE vol.27, № 82: p.21-42, Santiago de Chile. Edición electrónica disponible en

http://www.scielo.cl/scielo.php?script=sci_arttext\&pid=S025071612001008200002\&lng=es\&nrm=iso. (10-042008).

Sassen, S. (1996), La Ciudad Global, EUDEBA, Buenos Aires.

Idem (2004), "Una ciudad global paga un costo social alto, no es simplemente una fórmula para que todos estemos contentos. Entrevista a Saskia Sassen”, Revista Teína, № $4 . \quad$ Edición electrónica disponible en http://www.revistateina.com/teina/web/Teina4/dossiersassenverimpr.htm (13-02-2008).

Schutz, A. (1974), El problema de la realidad social, Amorrontu, Buenos Aires.

Sojo, C. (2002), "La noción de ciudadanía en el debate latinoamericano", Revista de la CEPAL, No 76, CEPAL: Santiago de Chile.

Touraine, A. (1987), El regreso del actor, Editorial Universitaria de Buenos Aires, Buenos Aires.

Idem (1994), La crítica de la modernidad, Fondo de cultura económica, Buenos Aires.

Idem (2000a), ¿Podremos vivir juntos? Iguales y diferentes, Fondo de Cultura Económica, Buenos Aires.

Idem (2000b), “A Method for Studying Social Actors", en Journal of World-Systems Research. Festschrift of Immanuel Wallerstein Part II. Vol. VI. N. 3: 900-918, Nueva York.

Idem (2006), Un nuevo paradigma para comprende el mundo de hoy, Paidós, Buenos Aires. 
REVISTA POLIS

VOL. $7 \mathrm{~N}^{0} 20,2008$

EL RECONOCIMIENTO EN EL OTRO: AUTOAFIRMACIÒN Y ACCIÒN COMUNICATIVA EN PERSONAS EN

EXTREMA EXCLUSIÒn, Págs. 105-132

(C) EDITORIAL DE LA UNIVERSIDAD BOLIVARIANA DE CHILE, 2008

Valda, D. (2007), Comparación de las distribuciones de ingreso de Chile con las de otros países, antes y después del gasto e impuestos, Consejo Asesor Presidencial, Santiago de Chile.

Vallejos, A; Ortí, Mata \& Agudo, M. (2007), Métodos y Técnicas de Investigación Social, Editorial Universitaria Ramón Areces, Madrid. 